\title{
A PROTEÇÃO JURÍDICA DO TRABALHADOR RURAL EM RELAÇÃO À UTILIZAÇÃO DOS AGROTÓXICOS
}

\author{
Eloy Pereira Lemos Júnior ${ }^{*}$ \\ Claysson Fidêncio Silva**
}

\begin{abstract}
RESUMO: O objetivo deste estudo foi verificar se a legislação brasileira atual protege o trabalhador rural dos efeitos nocivos da utilização de agrotóxicos nas lavouras. A pesquisa é de natureza teórico-bibliográfica, utilizando-se do método descritivo-dedutivo. O resultado alcançado foi de que o Brasil possui uma vasta legislação a respeito de prevenção de doença ocupacional e ou acidente de trabalho com relação à utilização de agrotóxicos.
\end{abstract}

PALAVRAS-CHAVE: Direitos Fundamentais; Relações do Trabalho; Trabalhador Rural; Agrotóxicos; Legislação.

\section{THE LEGAL PROTECTION OF THE RURAL WORKER IN RELATION TO THE USE OF PESTICIDES}

\begin{abstract}
The objective of this study was to verify if current brazilian legislation protects rural workers from the harmful effects of pesticide use in crops. The research is theoretical and bibliographical, using the descriptive-deductive method. The result was that Brazil has extensive legislation regarding the prevention of occupational disease and/or occupational accidents regarding the use of pesticides.
\end{abstract}

KEYWORDS: Fundamental rights; Labor Relations; Rural worker; Pesticides; Legislation.

\section{INTRODUÇÃO}

O consumo de agrotóxicos no Brasil aumentou consideravelmente na última década. Em 2017, o volume utilizado pelos produtores rurais foi de 539,9 mil toneladas, contra 361,6 mil toneladas em 2010. (MELO, 2019, on line)

\footnotetext{
* Doutor em Direito pela UFMG com pós-doutorado em Direito Empresarial (PUC-MG). Mestre. Especialista pela Universidade de Lisboa. Avaliador INEP/MEC. Professor de pós-graduação e graduação. Autor e avaliador de artigos qualificados CAPES. Pesquisador e advogado. eloy.junior@uol.com.br.

** Mestrando do PPGD - Mestrado em Direitos Fundamentais da Universidade de Itaúna-MG. Pós-graduado em Direito de Empresas pela Pontifícia Universidade Católica de Minas Gerais. Advogado. cfsbh@ yahoo.com.br.

Rev. Revista de Direitos Fundamentais nas Relações do Trabalho, Sociais e Empresariais| e-ISSN: 2525-9903| Evento Virtual| v. 6 | n. 1 | p. 62-79 | Jan/Jun. 2020
} 
Sendo assim, tendo em vista esse aumento considerável do volume utilizado de pesticidas nas lavouras brasileiras, a dúvida que se apresenta é se a legislação pátria está preparada para prevenir possíveis doenças ocupacionais e ou acidentes de trabalho do trabalhador rural manuseia, aplica, transporta e armazena estes produtos?

Este estudo é importante para a sociedade já que o trabalhador rural é a parte hipossuficiente na relação laboral e os efeitos nocivos do uso dos pesticidas podem levá-lo até a morte. Para a comunidade acadêmica esta pesquisa é importante tendo em vista o estudo e aperfeiçoamento da legislação brasileira vigente para o setor.

A hipótese é que o Brasil tenha uma legislação robusta e pronta para prevenir e solucionar demandas a respeito de doenças ocupacionais e ou acidente de trabalho com relação à utilização de agroquímicos.

Para se realizar esta pesquisa foi utilizado o método descritivo-dedutivo, utilizandose da pesquisa bibliográfica e documental.

$\mathrm{Na}$ primeira parte do trabalho pesquisou-se sobre a atividade agrícola, seu histórico, a Lei de Política Agrícola (Lei 8.171, de 17 de janeiro de 1991), a função social da propriedade e artigos da Constituição Federal de 1988 que tratam da atividade agrícola.

$\mathrm{Na}$ segunda parte desta pesquisa tratou-se do conceito de trabalhador rural previsto na Lei $5.889 / 73$, da dignidade da pessoa humana e dos direitos sociais. Tema de suma importância para entendimento do artigo.

A terceira e última parte deste estudo traz o conceito de agrotóxicos, descreve qual é o órgão responsável pela fiscalização do meio ambiente rural, trata dos principais pontos da Norma Regulamentadora 31, tais como, objetivos, obrigações do empregador e trabalhador rural, discorre sobre a Comissão Permanente Regional Rural (CPRR), sobre o Programa de Gestão de Segurança, Saúde e meio ambiente do Trabalhador Rural (PGSSMATR) e sobre diversos pontos a respeito dos agrotóxicos. Trata, também, das NR 15 e 16 e das principais convenções da Organização Internacional do Trabalho (OIT), que preveem normas protetivas para o trabalho no campo.

\section{ATIVIDADE AGRÍCOLA}

Rev. Revista de Direitos Fundamentais nas Relações do Trabalho, Sociais e Empresariais | e-ISSN: 2525-9903| Evento Virtual| v. 6 | n. 1 | p. $62-79$ | Jan/Jun. 2020 
A atividade agrícola começou acerca de 12 (doze) mil anos atrás quando o ser humano passou a domesticar algumas espécies de plantas como o trigo, ervilha e lentilhas. Até então, durante 2,5 (milhões) de anos, o homem coletava frutas, plantas e caçava para se alimentar (HARARI, 2017, p. 8 e 87).

No Brasil, a agricultura sempre teve um papel preponderante na economia. Atualmente, o país é o segundo maior produtor de soja do mundo, com uma produção de 114,843 milhões de toneladas na safra 2018/2019, atrás apenas dos Estados Unidos. Na produção de milho, o Brasil fica em terceiro lugar, com uma produção aproximada de 100 milhões de toneladas por ano. (EMBRAPA, 2020, on line)

Na Constituição Federal de 1988 estão as diretrizes da política agrícola brasileira, ressaltando que esta abrange as atividades agropecuárias, agroindustriais e de planejamento das atividades pesqueiras e florestal (RIZZARDO, 2015, p. 44).

$\mathrm{O}$ art. 187 da CF/88 determina que a política agrícola seja planejada e executada na forma da lei, com a participação dos produtores e trabalhadores rurais, levando-se em conta os “instrumentos creditícios e fiscais, os preços compatíveis com os custos de produção e a garantia de comercialização, o incentivo à pesquisa e à tecnologia, a assistência técnica e extensão rural, o seguro agrícola, o cooperativismo, a eletrificação rural e irrigação e a habitação para o trabalhador rural" (BRASIL, 1988).

A Lei 8.171, de 17 de janeiro de 1991, trata especificamente da política agrícola. O parágrafo único, do art. $1^{\circ}$ desta Lei, esclarece que se compreende como "atividade agrícola a produção, o processamento e a comercialização dos produtos, subprodutos e derivados, serviços e insumos agrícolas, pecuários, pesqueiros e florestais." (BRASIL, 1991)

$\mathrm{O}$ art. $2^{\circ}$, desta mesma Lei, informa que "a política agrícola tem como pressupostos que a atividade agrícola compreende processos físicos, químicos e biológicos, onde os recursos naturais envolvidos devem ser utilizados e gerenciados, subordinando-se às normas e princípios de interesse público, de forma que seja cumprida a função social e econômica da propriedade; que o processo de desenvolvimento agrícola deve proporcionar ao homem do campo o acesso aos serviços essenciais: saúde, educação, segurança pública, transporte, eletrificação, comunicação, habitação, saneamento, lazer e outros benefícios sociais." (BRASIL, 1991)

Rev. Revista de Direitos Fundamentais nas Relações do Trabalho, Sociais e Empresariais| e-ISSN: 2525-9903| Evento Virtual| v. 6 | n. 1 | p. 62-79| Jan/Jun. 2020 
Sendo assim, a lei que trata especificamente da política agrícola prevê que seja observado o bem estar do homem do campo, que lhe seja fornecido o básico para que tenha dignidade como qualquer outro trabalhador.

A CF/88 e o Estatuto da Terra, Lei 4.504, de 30 de novembro de 1964, tratam, também, da função social da propriedade. O art. 184, do primeiro diploma, determina que será desapropriado o imóvel rural por interesse social, para fins de reforma agrária, que não esteja cumprindo sua função social. $\mathrm{O} \S 1^{\circ}$, do art. $1^{\circ}$, do Estatuto da Terra, informa que Reforma Agrária é o conjunto de medidas que visa promover uma melhor distribuição da terra, a fim de atender aos princípios de justiça social e ao aumento de produtividade (RIZZARDO, 2015, p. 44 e 45$)$.

$\mathrm{O}$ art. 153 da $\mathrm{CF} / 88$, em seu inciso VI, determina a competência da União para instituir impostos sobre a propriedade territorial rural. $\mathrm{O} \S 4^{\circ}$ do mesmo artigo determina que “este imposto será progressivo e terá suas alíquotas fixadas de forma a desestimular a manutenção de propriedades improdutivas e não incidirá sobre pequenas glebas rurais, definidas em lei, quando as explore o proprietário que não possua outro imóvel”.

Quando se fala em função social da propriedade está querendo se adequar o direito de propriedade ao interesse coletivo, de tal forma a se excluir as características individualistas, excludentes e absolutas formadas durante a Idade Moderna (RIZZARDO, 2015, p. 50).

A Igreja Católica teve papel fundamental na formação do conceito da função social da terra. Todos os elementos presentes na Constituição Federal de 1988 que se refere à função social da terra encontram-se na Doutrina Social da Igreja (MORAIS e MELO, 2017, p. 41).

\section{TRABALHADOR RURAL}

Em que pese a importância histórica da atividade agrícola no Brasil, até 1930 existiam apenas leis esparsas que tratavam do trabalho urbano, em detrimento do trabalho rural. Mesmo com a aprovação da Consolidação das Leis do Trabalho (CLT), em 1943, o trabalhador rural não mereceu a atenção do legislador, o qual prestigiou unicamente o trabalhador urbano (NICOLAU, 2019, p. 92).

Rev. Revista de Direitos Fundamentais nas Relações do Trabalho, Sociais e Empresariais | e-ISSN: 2525-9903| Evento Virtual| v. 6 | n. 1 | p. 62-79 | Jan/Jun. 2020 
Somente em 1973, com a promulgação da Lei 5.889, o trabalhador rural obteve um diploma específico sobre seus direitos. O seu art. 13 determina que "nos locais de trabalho rural serão observadas as normas de segurança e higiene estabelecidas em portaria do ministro do Trabalho e Previdência Social.” Esta Lei foi regulamentada pelo Decreto 73.626/74.

Trabalhador rural é toda pessoa física que, em propriedade rural ou prédio rústico, presta serviços de natureza não eventual a empregador rural, sob a dependência deste e mediante salário, de acordo com o art. $2^{\circ}$, da Lei 5.889/73.

Com o advento da Constituição Federal de 1988 os direitos dos trabalhadores rurais foram igualados aos dos urbanos. Houve um avanço na regulamentação do meio ambiente do trabalhador rural e de suas condições de trabalho. (NICOLAU, 2019, p. 93)

A CF/88 trouxe como princípio fundamental a dignidade da pessoa humana e o valor social do trabalho. "O princípio da dignidade vincula o Estado e os particulares e compreende prestações positivas e negativas. Ele é norte para ponderação de interesses, limite para exercício de direitos, critério para identificação de direitos fundamentais e fontes de direitos não enumerados na Constituição.” (SARMENTO, 2016, p. 98).

Adriano Jannuzzi Moreira, reforçando a importância do princípio do valor social do trabalho, expôs que "o princípio do valor social do trabalho diz respeito à função que este exerce na sociedade, ou seja, é por meio do trabalho prestado com respeito ao Direito do Trabalho que a maioria das pessoas, destituídas de riqueza, tem a oportunidade de, além de promover seu sustento próprio e de sua família, melhorar a sua condição de vida" (MOREIRA, 2015, p. 100).

Ingo Wolfgang Sarlet relatou a importância que a CF/88 reservou para os Direitos Sociais:

\begin{abstract}
Além de serem reconhecidos como direitos fundamentais ainda receberam título próprio. Por isso, os direitos fundamentais sociais devem ser compreendidos por uma dogmática constitucional singular, emancipatória, marcada pelo compromisso com a dignidade da pessoa humana e com a plena efetividade dos comandos constitucionais. (SARLET, 2006, p. 59)
\end{abstract}

Graciane Rafisa Saliba teceu o seguinte comentário sobre os direitos sociais:

Os direitos sociais envolvem garantias de trabalho e de remuneração, condições mínimas de condições econômicas bem como oportunidade de acesso ao mercado em condições dignas. Para cumprimento desses direitos há também que se observar

Rev. Revista de Direitos Fundamentais nas Relações do Trabalho, Sociais e Empresariais| e-ISSN: 2525-9903| Evento Virtual| v. 6 | n. 1 | p. 62-79| Jan/Jun. 2020 
os direitos trabalhistas, as garantias previdenciárias e assistenciais, tais como aposentadoria e seguro-desemprego. Esses direitos devem ser consagrados em legislações internas dos Estados, o que possibilita uma diferenciação, pois nem sempre são abordados com a mesma amplitude e definição. Em algumas situações a consagração do direito se deu através de política de governo, com uma inspiração Keynesiana. Nesse período as transformações tecnológicas e gerenciais foram conciliadas com a manutenção e ampliação do emprego, o que acarretou a redução da desigualdade em grande parte do mundo capitalista (SALIBA, 2014, p. 30).

Feitos os apontamentos acima, segue a pesquisa adentrando-se no capítulo que cuida dos agrotóxicos e as normas de segurança direcionadas ao trabalhador, em busca de manter-se os direitos fundamentais na relação de trabalho.

\section{AGROTÓXICOS E AS NORMAS DE SEGURANÇA E SAÚDE NO TRABALHO}

\subsection{Agrotóxicos na atualidade brasileira e sua definição}

Os agrotóxicos passaram a merecer uma atenção especial das autoridades brasileiras e estudiosos há alguns anos, já que o volume utilizado desses produtos nas lavouras do país cresceu consideravelmente, principalmente desde o início dos anos 2000. Segundo estudo realizado pela pesquisadora Larissa Mies Bombardi (2019, on line), “entre 2000 e 2010, cresceu em $100 \%$ o uso de pesticidas no planeta, no mesmo período em que o aumento no Brasil chegou a quase $200 \% "$.

Atualmente, o Brasil é um dos países que mais utilizam agrotóxicos no mundo, com um volume que ultrapassou as 500 mil toneladas no ano de 2017. (MELO, 2019, on line)

Gladstone Leonel Júnior e Pedro Helmold comentam sobre o aumento da utilização dos agroquímicos nas lavouras brasileiras:

\footnotetext{
Outro aspecto fundamental relativo à problemática agrícola e ao estímulo à utilização de agrotóxicos nos últimos anos foi a Lei ${ }^{\circ} 11.105$, de 24 de março de 2005, atual lei de biossegurança, que veio a substituir a Lei $n^{\circ} 8.974$, de 05 de janeiro de 1995. Ambas relativas ao uso agrícola das técnicas de engenharia genética, ou seja, dispõe sobre o cultivo dos transgênicos. Esta lei concedeu poder vinculante às decisões da Comissão Técnica Nacional de Biossegurança (CTNBio) a respeito da liberação para uso de transgênicos, gerando situações preocupantes e contraditórias relativas à facilitação do uso de sementes transgênicas no Brasil (LEONEL JÚNIOR; HELMOLD, 2018, p. 198)
}

Rev. Revista de Direitos Fundamentais nas Relações do Trabalho, Sociais e Empresariais | e-ISSN: 2525-9903| Evento Virtual| v. 6 | n. 1 | p. 62-79 | Jan/Jun. 2020 
Os mesmos autores acima dissertam um pouco mais sobre a questão:

Uma das principais promessas feitas pelos defensores dos OGM, com a aprovação da lei de biossegurança, era de que o cultivo dos mesmos, entre outros benefícios, traria a diminuição do uso de agrotóxicos, em função do desenvolvimento genético de plantas resistentes a pragas. Porém, isso não se traduziu para a realidade, de acordo com o dossiê ABRASCO (2015, p. 113). A venda de sementes transgênicas é casada com a dos agrotóxicos, uma vez que frequentemente são produzidos pelas mesmas empresas. A monocultura, aliada à utilização dos pesticidas acaba por realizar a seleção de pragas resistentes a esses venenos, o que estimula os produtores a aumentarem a quantidade de pesticida aplicado, assim como utilizar outros tipos de agrotóxicos em conjunto (LEONEL JÚNIOR; HELMOLD, 2018, p. 199).

Os agrotóxicos, também chamados de pesticidas, defensivos agrícolas ou agroquímicos, são produtos e agentes de processos físicos, químicos ou biológicos, utilizados nos setores de produção, armazenamento e beneficiamento de produtos agrícolas, pastagens, proteção de florestas, nativas ou plantadas, e de outros ecossistemas e de ambientes urbanos, hídricos e industriais. Visa alterar a composição da flora ou da fauna, a fim de preservá-las da ação danosa de seres vivos considerados nocivos. Também são considerados agrotóxicos as substâncias e produtos empregados como desfolhantes, dessecantes, estimuladores e inibidores de crescimento.

\title{
4.2 Norma Regulamentadora 31
}

Tendo em vista o grande volume de agrotóxicos utilizado na atualidade pelos agricultores brasileiros a preocupação com a saúde do trabalhador do campo aumentou da mesma forma entre os estudiosos e autoridades.

A fiscalização das normas de higiene e segurança do trabalho é realizada pela Secretaria de Trabalho do Ministério da Economia.

Adriano Jannuzzi Moreira discorreu acerca da prevenção em matéria de segurança e saúde no trabalho:

\begin{abstract}
A prevenção de riscos profissionais proporciona um ambiente de trabalho mais seguro e agradável aos trabalhadores promovendo sua dignidade e o valor social do trabalho, além de representar a diminuição de custos para a empresa, decorrentes, dentre outros, de condenações judiciais, multas aplicadas pela fiscalização do trabalho e ações regressivas do INSS. Em última análise proporciona um aumento
\end{abstract}

Rev. Revista de Direitos Fundamentais nas Relações do Trabalho, Sociais e Empresariais | e-ISSN: 2525-9903| Evento Virtual| v. 6 | n. 1 | p. 62-79| Jan/Jun. 2020 
de produtividade do trabalhador que exerce suas atividades de maneira saudável e com tranquilidade (MOREIRA, 2015, p. 124 e 125).

A principal norma regulamentadora (NR) do ambiente do trabalhador rural é a NR 31 que dispõe sobre a segurança e saúde no trabalho na agricultura, pecuária, silvicultura, exploração florestal e aquicultura e entrou em vigor com a publicação da Portaria MTE n. ${ }^{\circ}$ 86, de 03 de março de 2005.

Compete ao Departamento de Segurança e Saúde no Trabalho (DSST), órgão que faz parte da Secretaria de Trabalho, definir, coordenar, orientar e implementar a política nacional em segurança e saúde no trabalho rural. Para isto, cabe a este Departamento identificar os principais problemas de segurança e saúde do setor, estabelecendo as prioridades de ação, desenvolvendo os métodos efetivos de controle dos riscos e de melhoria das condições de trabalho, avaliar periodicamente os resultados da ação, prescrever medidas de prevenção dos riscos no setor observado os avanços tecnológicos, os conhecimentos em matéria de segurança e saúde, avaliar permanentemente os impactos das atividades rurais no meio ambiente de trabalho, elaborar recomendações técnicas para os empregadores e empregados e para trabalhadores autônomos observados os usos e costumes regionais, dentre outras atribuições, de acordo com o item 31.3.1 da NR 31.

A Norma Regulamentadora 31 estipula obrigações para o empregador rural e equiparados. Dentre as diversas obrigações destaca-se a de garantir adequadas condições de trabalho, higiene e conforto, segundo as especificidades de cada atividade e as características de cada região, a de realizar avaliações dos riscos para a segurança e saúde dos trabalhadores e, com base nos resultados, adotar medidas de prevenção e proteção para garantir que todas as atividades, lugares de trabalho, máquinas, equipamentos, ferramentas e processos produtivos sejam seguros e em conformidade com as normas de segurança e saúde, a de promover melhorias nos ambientes e nas condições de trabalho, de forma a preservar o nível de segurança e saúde dos trabalhadores, a de cumprir e fazer cumprir as disposições legais e regulamentares sobre segurança e saúde no trabalho, a de analisar, com a participação da Comissão Interna de Prevenção de Acidentes no Trabalho Rural - CIPATR, as causas dos acidentes e das doenças decorrentes do trabalho, buscando prevenir e eliminar as possibilidades de novas ocorrências, dentre outras, segundo o item 31.3.3 da aludida Norma.

Rev. Revista de Direitos Fundamentais nas Relações do Trabalho, Sociais e Empresariais| e-ISSN: 2525-9903| Evento Virtual| v. 6 | n. 1 | p. $62-79$ | Jan/Jun. 2020 
Adriano Jannuzzi Moreira comentou a respeito dos acidentes e doenças ocupacionais:

\begin{abstract}
Os acidentes de trabalho e as doenças ocupacionais provocam gravíssimas repercussões tanto no ambiente empresarial, gerando medo e insegurança nos trabalhadores e onerando muito o empregador, quanto no campo jurídico, por meio de ações de indenização por danos morais, materiais e estéticos, regressivas do INSS, responsabilidade penal e administrativa, estendo seus efeitos para a sociedade como um todo (MOREIRA, 2015, p. 124)
\end{abstract}

Os trabalhadores rurais também devem cumprir diversas obrigações para a melhoria do ambiente de trabalho. Devem agir de acordo com as determinações sobre as formas seguras de desenvolver suas atividades, especialmente quanto às Ordens de Serviço para esse fim, adotar as medidas de proteção determinadas pelo empregador, sob pena de constituir ato faltoso a recusa injustificada, submeter-se aos exames médicos e colaborar com a empresa na aplicação desta Norma Regulamentadora.

A NR 31 cria a Comissão Permanente Regional Rural (CPRR), no âmbito de cada Delegacia Regional do Trabalho (DRT), que tem como prerrogativas mais importantes estudar e propor medidas para o controle e a melhoria das condições e dos ambientes de trabalho rural, de realizar estudos, com base nos dados de acidentes e doenças decorrentes do trabalho rural, de incentivar estudos e debates visando o aperfeiçoamento permanente desta NR. A CPRR será composta de representantes do governo, dos trabalhadores e dos empregadores.

Os empregadores rurais devem elaborar e executar o Programa de Gestão de Segurança, Saúde e Meio Ambiente do Trabalho Rural (PGSSMATR), mediante ações de segurança e saúde que possa prevenir acidentes e doenças. Deve-se observar a seguinte ordem de prioridade: a) eliminação de riscos através da substituição ou adequação dos processos produtivos, máquinas e equipamentos; b) adoção de medidas de proteção coletiva para controle dos riscos na fonte; c) adoção de medidas de proteção pessoal.

No intuito de implementar as ações de segurança e saúde no ambiente de trabalho rural, a NR 31 determina que o empregador rural contrate Serviço Especializado em Segurança e Saúde no Trabalho Rural (SESTR). O SESTR é composto de profissionais especializados objetivando ações técnicas integradas às práticas de gestão de segurança, saúde e meio ambiente de trabalho. O SESTR tem como funções assessorar empregadores e trabalhadores, promover e desenvolver atividades educativas em saúde e segurança para todos

Rev. Revista de Direitos Fundamentais nas Relações do Trabalho, Sociais e Empresariais | e-ISSN: 2525-9903| Evento Virtual| v. 6 | n. 1 | p. 62-79| Jan/Jun. 2020 
os trabalhadores, identificar e avaliar os riscos para a segurança e saúde dos trabalhadores em todas as fases do processo de produção, indicar medidas de eliminação, controle ou redução dos riscos, priorizando a proteção coletiva, monitorar periodicamente a eficácia das medidas adotadas, analisar as causas dos agravos relacionados ao trabalho e indicar as medidas corretivas e preventivas pertinentes, participar dos processos de concepção e alterações dos postos de trabalho, escolha de equipamentos, tecnologias, métodos de produção e organização do trabalho, para promover a adaptação do trabalho ao homem, intervir imediatamente nas condições de trabalho que estejam associadas a graves e iminentes riscos para a segurança e saúde dos trabalhadores, estar integrado com a CIPATR, valendo-se, ao máximo, de suas observações, além de apoiá-la, treiná-la e atendê-la nas suas necessidades e solicitações, manter registros atualizados referentes aos monitoramentos e avaliações das condições de trabalho, indicadores de saúde dos trabalhadores, acidentes e doenças do trabalho e ações desenvolvidas pelo SESTR.

A NR 31, em seu item 31.3.5, elenca vários direitos dos trabalhadores rurais, tais como, laborar em ambientes de trabalho, seguros e saudáveis, ser consultados, através de seus representantes na Comissão Interna de Prevenção de Acidentes do Trabalho Rural (CIPATR), sobre as medidas de prevenção que serão adotadas pelo empregador, escolher sua representação em matéria de segurança e saúde no trabalho, receber instruções em matéria de segurança e saúde, bem como orientação para atuar no processo de implementação das medidas de prevenção que serão adotadas pelo empregador.

A NR 31 cria a Comissão Permanente Regional Rural (CPRR), no âmbito de cada Delegacia Regional do Trabalho (DRT), que tem como prerrogativas mais importantes estudar e propor medidas para o controle e a melhoria das condições e dos ambientes de trabalho rural, de realizar estudos, com base nos dados de acidentes e doenças decorrentes do trabalho rural, de incentivar estudos e debates visando o aperfeiçoamento permanente desta NR. A CPRR será composta de representantes do governo, dos trabalhadores e dos empregadores.

De acordo com o item 31.5.1.3.11, desta Norma, quando ocorrer doença ocupacional, o empregador deverá fazer Comunicação de Acidente do Trabalho (CAT), afastando o trabalhador das suas funções habituais e o encaminhando à previdência social, através de laudo médico.

Rev. Revista de Direitos Fundamentais nas Relações do Trabalho, Sociais e Empresariais| e-ISSN: 2525-9903| Evento Virtual| v. 6 | n. 1 | p. $62-79$ | Jan/Jun. 2020 
A Norma Regulamentadora 31 dispõe também sobre agrotóxicos, adjuvantes e produtos afins, em seu item 31.8. Adjuvantes são produtos que ao ser misturados com outros lhe reforçam a ação.

Os trabalhadores que manipulam os agrotóxicos, adjuvantes e produtos afins, em qualquer uma das etapas de armazenamento, transporte, preparo, aplicação, descarte, e descontaminação de equipamentos e vestimentas são considerados trabalhadores em exposição direta. Os trabalhadores que não manipulam diretamente os agrotóxicos, adjuvantes e produtos afins, mas circulam e desempenham suas atividades de trabalho em áreas vizinhas aos locais onde se faz a manipulação dos agrotóxicos em qualquer uma das etapas de armazenamento, transporte, preparo, aplicação e descarte, e descontaminação de equipamentos e vestimentas, e ou ainda os que desempenham atividades de trabalho em áreas recém-tratadas, são considerados trabalhadores em exposição indireta.

De acordo com o item 31.8.2 da NR 31, é proibida a manipulação de quaisquer agrotóxicos, adjuvantes e produtos afins que não estejam registrados e autorizados pelos órgãos governamentais competentes. No item seguinte, 31.8.3, a Norma preleciona que é proibida a manipulação por menores de dezoito anos, maiores de sessenta anos e por gestantes.

A NR 31 também veda a manipulação de quaisquer agrotóxicos, adjuvantes e produtos afins, nos ambientes de trabalho, em desacordo com a receita e as indicações do rótulo e bula, previstos em legislação vigente, o trabalho em áreas recém-tratadas, antes do término do intervalo de reentrada estabelecido nos rótulos dos produtos, salvo com o uso de equipamento de proteção recomendado e a entrada e permanência de qualquer pessoa na área a ser tratada durante a pulverização aérea.

Os trabalhadores expostos diretamente devem receber treinamento dos empregadores para prevenir acidentes com agrotóxicos. Estes treinamentos devem ser realizados por órgãos e serviços oficiais de extensão rural, instituições de ensino de nível médio e superior em ciências agrárias, Serviço Nacional de Aprendizagem Rural (SENAR), pelo SESTR do empregador rural ou equiparado.

A Norma Regulamentadora 31, em seu tópico 31.8.9, dispõe que o empregador rural ou equiparado deve fornecer equipamentos de proteção individual (EPI) e vestimentas

Rev. Revista de Direitos Fundamentais nas Relações do Trabalho, Sociais e Empresariais | e-ISSN: 2525-9903| Evento Virtual| v. 6 | n. 1 | p. 62-79| Jan/Jun. 2020 
adequadas aos riscos, que não propiciem desconforto térmico prejudicial ao trabalhador; fornecer os equipamentos de proteção individual e vestimentas de trabalho em perfeitas condições de uso e devidamente higienizados, responsabilizando-se pela descontaminação dos mesmos ao final de cada jornada de trabalho, e substituindo-os sempre que necessário; orientar quanto ao uso correto dos dispositivos de proteção; disponibilizar um local adequado para a guarda da roupa de uso pessoal; fornecer água, sabão e toalhas para higiene pessoal; garantir que nenhum dispositivo de proteção ou vestimenta contaminada seja levado para fora do ambiente de trabalho; garantir que nenhum dispositivo ou vestimenta de proteção seja reutilizado antes da devida descontaminação; vedar o uso de roupas pessoais quando da aplicação de agrotóxicos.

O empregador rural deve ter cuidados especiais com os equipamentos de aplicação de agrotóxicos. Deve mantê-los em perfeito estado de conservação e funcionamento; inspecioná-los antes de cada aplicação; utilizá-los somente para a finalidade indicada; operálos dentro dos limites, especificações e orientações técnicas.

\subsection{Normas Regulamentadoras 15 e 16}

As normas regulamentadoras (NR) 15 e 16 são de grande importância para a segurança e saúde do trabalhador. Elas regulamentam as atividades insalubres e perigosas, respectivamente.

Aplicam-se subsidiariamente as normas urbanas, nos casos em que forem omissas as rurais, nos termos do art. 13 da Lei $\mathrm{n}^{\circ}$ 5.889/73, quando se trata de saúde e segurança do trabalho e de seu ambiente. (NICOLAU, 2019, p. 98)

São consideradas atividades insalubres as que são praticadas acima dos níveis de tolerância previstas nos anexos de $\mathrm{n}^{\mathrm{o}} 1,2,3,5,11$ e 12, de acordo com o item 15.1.1, da NR 15.

As atividades contidas nos anexos de $n^{\circ} 6,13,14$, da mesma forma, são consideradas insalubres para fins da NR 15, item 15.1.3.

Entende-se também como atividades insalubres as que são comprovadas mediante laudo de inspeção do local de trabalho, constantes dos anexos de $\mathrm{n}^{\circ}$ 7, 8, 9 e 10.

Rev. Revista de Direitos Fundamentais nas Relações do Trabalho, Sociais e Empresariais | e-ISSN: 2525-9903 | Evento Virtual| v. 6 | n. 1 | p. $62-79$ | Jan/Jun. 2020 
Por sua vez, as atividades perigosas estão relacionadas nos anexos da NR 16, de acordo com o item 16.1 desta Norma.

Quando laborar em condições de periculosidade, o trabalhador rural terá direito ao adicional de 30\% (trinta por cento), incidente sobre o salário, sem os acréscimos resultantes de gratificações, prêmios ou participação nos lucros da empresa, de acordo com o item 16.2, da NR 16.

De acordo com o item 16.2.1, o empregado poderá optar pelo adicional de insalubridade que porventura lhe seja devido.

\subsection{Convenções da Organização Internacional do Trabalho}

As convenções da Organização Internacional do Trabalho (OIT) se apresentam como importantes instrumentos jurídicos para a proteção do trabalhador do campo.

A CF/88 determinou a forma como essas convenções serão incorporadas no Direito interno. $\mathrm{O}$ art. 21 preleciona que: "Compete a União manter relações com Estados estrangeiros e participar de organizações internacionais". Já o art. 49, I, informa que compete exclusivamente ao Congresso Nacional resolver definitivamente sobre tratados, acordos ou atos internacionais que acarretem encargos ou compromissos gravosos ao patrimônio nacional. Ao Presidente da República, compete privativamente, segundo o art. 84, VIII, "celebrar tratados, convenções e atos internacionais, sujeitos a referendo do Congresso Nacional”.

Para uma convenção da OIT fazer parte da legislação brasileira é necessário, primeiramente, que o Presidente da República participe das negociações a nível internacional, assine o instrumento e o encaminhe ao Congresso Nacional. Após apreciar, o Congresso enviará a convenção referendada ao Presidente da República, mediante decreto legislativo. O Poder Executivo Federal, então, vai promulgar e publicar a convenção. Esta convenção equivale às leis ordinárias.

As convenções e tratados internacionais que possuem como objeto direitos humanos, se equiparam às emendas constitucionais. Mas, deverão, obrigatoriamente, passar pelas duas

Rev. Revista de Direitos Fundamentais nas Relações do Trabalho, Sociais e Empresariais | e-ISSN: 2525-9903| Evento Virtual| v. 6 | n. 1 | p. 62-79| Jan/Jun. 2020 
Casas do Congresso Nacional e ser aprovadas, em cada uma delas, por três quintos dos seus membros, de acordo com o parágrafo $3^{\circ}$, do art. $5^{\circ}$, da $\mathrm{CF} / 88$.

O Direito brasileiro incorporou importantes convenções da OIT que protegem o trabalhador rural. Tendo em vista o objeto da nossa pesquisa, a Convenção de $n^{\circ} 170$ é de extrema importância.

Rodrigo Borges Nicolau, em seu artigo para a Revista Brasileira de Direitos Humanos, publicada no ano anterior, nos informa que:

\begin{abstract}
Essa Convenção cuida das atividades laborais que envolvam o contato do trabalhador com algum produto químico. Esse contato ou exposição do trabalhador pode ocorrer na produção desses produtos, no seu manuseio, armazenamento, transporte, eliminação e tratamento dos resíduos, na emissão de produtos químicos resultantes do trabalho, e também na manutenção, reparação e limpeza de equipamentos e recipientes que continham essas substâncias (NICOLAU, 2019, p. 107).
\end{abstract}

A Convenção $n^{\circ} 148$ trata da proteção dos trabalhadores contra os riscos profissionais devidos à contaminação do ar, ao ruído e às vibrações no local de trabalho e foi aprovado pelo Decreto Legislativo no 56 , de 9 de outubro de 1981.

$\mathrm{O}$ art. 3, dessa Convenção, informa que a expressão "contaminação do ar", compreende o ar contaminado por substâncias que, qualquer que seja seu estado físico, sejam nocivas à saúde ou contenham qualquer outro tipo de perigo. (BRASIL, 1986)

Outra importante convenção da OIT que foi incorporado pelo Direito interno brasileiro é a 155, que dispõe acerca da segurança e saúde dos trabalhadores e o meio ambiente de trabalho.

Em seu art. 4, ela determina que o Estado Membro deverá formular, colocar em prática e reavaliar periodicamente uma política nacional coerente em matéria de segurança e saúde dos trabalhadores e o meio ambiente de trabalho. Tudo isto, em conformidade com as condições e práticas nacionais e após consulta às organizações mais representativas de empregadores e trabalhadores. (BRASIL, 1994)

A Convenção 161 da OIT trata dos serviços de saúde do trabalho e em seu art. 15, determina que estes deverão ser informados dos casos de doença entre os trabalhadores e das

Rev. Revista de Direitos Fundamentais nas Relações do Trabalho, Sociais e Empresariais | e-ISSN: 2525-9903| Evento Virtual| v. 6 | n. 1 | p. $62-79$ | Jan/Jun. 2020 
faltas ao serviço por motivos de saúde, a fim de estarem aptos a identificar toda relação que possa existir entre as causas da doença ou da falta ao serviço. (BRASIL, 1991)

\section{CONSIDERAÇÕES FINAIS}

Com o crescente emprego dos agrotóxicos nas lavouras brasileiras, torna-se necessário saber se a legislação brasileira encontra-se preparada para possíveis demandas.

Nesse sentido, esta pesquisa buscou saber se o Brasil está preparado juridicamente para este aumento na utilização de agroquímicos.

A base do estudo em tela foi a Constituição Federal de 1988, a Lei 4.504/64 (Estatuto da Terra), a Lei 8.171/91 (Lei da Política Agrícola), a Norma Regulamentadora 31 e as Convenções OIT de nº 148,155 e 161.

Na Constituição Federal, este trabalho se amparou nos conceitos de dignidade da pessoa humana, os valores sociais do trabalho, os direitos sociais, a função social da propriedade.

O Estatuto da Terra trata da função social da propriedade, determinando que será desapropriado o imóvel rural, para fins de reforma agrária, que não esteja cumprindo sua função social.

A política agrícola é tratada especificamente na Lei 8.171/91. Esta Lei define o que seja a atividade agrícola, menciona a função social da propriedade, e "que o processo de desenvolvimento agrícola deve proporcionar ao homem do campo o acesso aos serviços essenciais: saúde, educação, segurança pública, transporte, eletrificação, comunicação, habitação, saneamento, lazer e outros benefícios sociais".

As minucias da legislação sobre ambiente de trabalho rural, a segurança e saúde do trabalho encontrou-se na Norma Regulamentadora 31. Nesta norma vislumbrou-se também o Programa de Gestão de Segurança e Saúde e Meio Ambiente do Trabalho Rural (PGSSMATR) e o Serviço Especializado em Segurança e Saúde no Trabalho Rural (SESTR).

A conclusão que se chegou, após esta pesquisa, é que a legislação brasileira está preparada para dar o suporte necessário, orientar e prevenir doenças ocupacionais em decorrência do aumento da utilização de agrotóxicos nas lavouras brasileiras. Há leis bastante

Rev. Revista de Direitos Fundamentais nas Relações do Trabalho, Sociais e Empresariais| e-ISSN: 2525-9903| Evento Virtual| v. 6 | n. 1 | p. 62-79| Jan/Jun. 2020 
detalhadas, como a Norma Regulamentadora 31, que tratam do meio ambiente laboral, fornecendo as diretrizes para tornar possível a conciliação entre o desenvolvimento das atividades agrícolas e a segurança e saúde do trabalhador rural.

Entretanto, é sabido que possuir apenas a legislação protetiva ao trabalhador rural não elimina ou reduz os acidentes de trabalho e doenças ocupacionais decorrentes do uso excessivo ou inadequado de agrotóxicos. É de extrema importância que o país tenha também uma fiscalização eficiente, garantindo assim os direitos fundamentais do trabalhador e a eficiência nas relações de trabalho, além de projetos de conscientização sobre o uso adequado nas duas pontas da relação, qual seja, junto aos empregados e empregadores.

\section{REFERÊNCIAS}

BOMBARDI, Larissa Mies. Afinal, o Brasil é o maior consumidor de agrotóxico do mundo? Revista Galileu. Disponível em: https://revistagalileu.globo.com/Ciencia/MeioAmbiente/noticia/2019/06/afinal-o-brasil-e-o-maior-consumidor-de-agrotoxico-domundo.html. Acesso em: 01 mar. 2020.

BRASIL. Constituição da República Federativa do Brasil de 1988. Disponível em: http://www.planalto.gov.br/ccivil_03/constituicao/constituicao.htm. Acesso em: 08 jan. 2020.

BRASIL. Decreto n⿳93.413/1986. Promulga a Convenção no 148 da OIT. Disponível em http://www.planalto.gov.br/ccivil_03/decreto/1980-1989/D93413.htm. Acesso em: 09 jan. 2020.

BRASIL. Decreto no 1.254/1994. Promulga a Convenção no 155 da OIT. Disponível em http://www.planalto.gov.br/ccivil_03/decreto/1990-1994/D1254.htm. Acesso em: 09 jan. 2020.

BRASIL. Decreto n¹27/1991. Promulga a Convenção no 161 da OIT. Disponível em http://www.planalto.gov.br/ccivil_03/decreto/1990-1994/D0127.htm. Acesso em: 09 jan. 2020.

BRASIL. Decreto no 2.657/1998. Promulga a Convenção no 170 da OIT. Disponível em http://www.planalto.gov.br/ccivil_03/decreto/D2657.htm. Acesso em: 09 jan. 2020.

BRASIL. Empresa Brasil de Comunicação. Safra soja e milho.

Disponível em: http://agenciabrasil.ebc.com.br/economia/noticia/2019-08/conab-estima-safrarecorde-de-graos-para-safra-20182019. Acesso em: 07 jan. 2020.

BRASIL. Lei n ${ }^{\circ}$ 4.504/1964. Dispõe sobre o Estatuto da Terra, e dá outras providências. Disponível em: http://www.planalto.gov.br/ccivil_03/leis/14504.htm. Acesso em: 08 jan. 2020.

Rev. Revista de Direitos Fundamentais nas Relações do Trabalho, Sociais e Empresariais| e-ISSN: 2525-9903| Evento Virtual| v. 6 | n. 1 | p. $62-79$ | Jan/Jun. 2020 
BRASIL. Lei n 8.171/1991. Dispõe sobre a Política Agrícola. Disponível em: http://www.planalto.gov.br/ccivil_03/LEIS/L8171.htm. Acesso em: 07 jan. 2020.

BRASIL. Ministério da Agricultura. Conceito de Agrotóxicos.

Disponível em:http://www.agricultura.gov.br/assuntos/insumos-agropecuarios/insumosagricolas/agrotoxicos. Acesso em: 08 jan. 2020.

BRASIL. Norma Regulamentadora 15. Disponível em: http://trabalho.gov.br/seguranca-esaude-no-trabalho/normatizacao/normas-regulamentadoras/norma-regulamentadora-n-15atividades-e-operacoes-insalubres. Acesso em: 09 jan. 2020.

BRASIL. Norma Regulamentadora 16. Disponível em: http://trabalho.gov.br/images/Documentos/SST/NR/NR16.pdf. Acesso em: 09 jan. 2020.

BRASIL. Norma Regulamentadora 31. Disponível em: http://www.trtsp.jus.br/geral/tribunal2/LEGIS/CLT/NRs/NR_31.html. Acesso em: 09 jan. 2020 .

EMBRAPA - Empresa Brasileira de Pesquisa Agropecuária. Soja em números (safra 2018/19). Disponível em: https://www.embrapa.br/soja/cultivos/soja1/dadoseconomicos\#collapse_fhuc_1. Acesso em 01 mar. 2020.

HARARI, Yuval Noah. Uma breve história da humanidade. 1976. Tradução Janaína Marcoantonio. 21 ed. Porto Alegre, RS: L\&PM, 2017.

LEONEL JÚNIOR, Gladstone; HELMOLD, Pedro. Revista de Direito Agrário. Instituto Nacional de Colonização e Reforma Agrária. Ano 21, no 22. Brasília: Incra, 2018.

MELO, Luísa. Brasil usa 500 mil toneladas de agrotóxicos por ano, mas quantidade pode ser reduzida, dizem especialistas. G1. Notícias [online]. Disponível em:

https://g1.globo.com/economia/agronegocios/noticia/2019/05/27/brasil-usa-500-miltoneladas-de-agrotoxicos-por-ano-mas-quantidade-pode-ser-reduzida-dizemespecialistas.ghtml. Acesso em: 07 jan. 2020.

MORAIS, Márcio Eduardo Senra Nogueira Pedrosa, organizador. Caderno de Direitos Humanos, Liberdade Religiosa e Tolerância. v. 2. Pará de Minas, MG: VirtualBooks Editora, 2017.

MOREIRA, Adriano Jannuzzi. Trabalho \& Saúde / Vitor Salino de Moura Eça, coordenador - Belo Horizonte: RTM, 2015.

NICOLAU, Rodrigo Borges. Meio Ambiente do Trabalho e Agrotóxicos. Revista Brasileira de Direitos Humanos. n. 30, Jul/Set 2019. 
RIZZARDO, Arnaldo. Curso de Direito Agrário. 3. ed. rev., atual. e ampl. São Paulo: Revista dos Tribunais, 2015.

SARMENTO, Daniel. Dignidade da Pessoa Humana. Belo Horizonte: Fórum, 2016.

SALIBA, Graciane Rafisa. Convenções da OIT \& Empresas Transnacionais: em busca da efetivação dos direitos trabalhistas. Rio de Janeiro: Lumen Juris, 2014.

SARLET, Ingo Wolfgang. Dignidade da pessoa humana e direitos fundamentais na Constituição Federal de 1988. 4. ed. Porto Alegre: Livraria do Advogado, 2006. 